\title{
SOLUBILITY, DUCTILITY AND RESILIENCE OF A PMMA DENTURE RESIN WITH GRAPHENE AND SILVER NANOPARTICLES ADDITION
}

\author{
CECILIA BACALI ${ }^{a}$, SMARANDA BUDURU ${ }^{a}$, \\ VIVI NASTASE ${ }^{b}$, ANTARINIA CRACIUN $^{a}$, DOINA PRODAN ${ }^{c}$, \\ MARIANA CONSTANTINIUC ${ }^{a}$, MANDRA BADEA ${ }^{a}$, \\ MARIOARA MOLDOVAN ${ }^{c}$, CODRUTA SAROSI ${ }^{*}$
}

\begin{abstract}
PMMA denture base materials are used for several decades without significant improvements in their composition. The addition of different fillers has been proved to improve some of the acrylic resin's characteristics. Recent studies focused on enhancing PMMA properties using nanoparticles. In our study we assessed the effect of adding graphene and silver nanoparticles on the solubility, ductility and resilience of a commercial denture base acrylic resin.
\end{abstract}

Keywords: solubility PMMA, ductility, resilience acrylic resin, graphene, silver nanoparticles

\section{INTRODUCTION}

Acrylic resins have a wide applicability in medicine and among them PMMA are the most used materials in denture fabrication because of their convenient characteristics, such as dimensional stability, ease of handling and processing [1]. However, they are brittle materials with low fracture strength and insufficient surface hardness [2]. Since PMMA resins are relatively brittle

\footnotetext{
a Iuliu Hatieganu University of Medicine and Pharmacy, Department of Prosthodontics and Dental Materials, 32 Clinicilor str, RO-400006, Cluj-Napoca, Romania

b Institute for Computational Linguistics, University of Heidelberg, Im Neuenheimerfeld 325, Heidelberg, 69120, Germany

c Babes Bolyai University - Institute of Chemistry Raluca Ripan, Department of Polymer Composites, 30 Fantanele str., RO-400294, Cluj-Napoca, Romania

*Corresponding author: codruta.sarosi@gmail.com
} 
materials and they are subjected to high mastication forces or sometimes to accidental drops, several attempts have been made to improve its mechanical properties by adding fillers of different type and sizes [3]. Inorganic nanofillers have a large surface area which determines a high surface energy at the interface of polymer matrix, improving flexural strength; they improve hardness due to their rigidity and higher stiffness than the matrix [4] and the fracture toughness as well, because of the more uniform distribution compared to micro fillers [5]. Addition of silver nanoparticles to PMMA has several favorable effects: antimicrobial activity, increased monomer conversion, increased flexural strength and elastic modulus, improved thermal stability [6]. Tripathy showed that graphene oxide incorporation into PMMA determines improved mechanicaltensile strength, Young's modulus, strain at break, thermal and electrical properties of the material [7]. The improvement of the characteristics of denture base materials is focused mainly on the mechanical properties and among them on fracture strength. Fractures in composites depend on the heterogeneity, interfacial adhesion between the materials' components, type of fracture and on the brittle or ductile nature of the components [8]. Zhang found that the higher the tensile strain and added fiber concentration the lower the ductility, while a higher break strain is linked to a higher ductility in the studied composites.

Rubberlike materials added to acrylic resins can improve the fracture strength [9]. Muraikami [10] and Alhareb [11] showed that by adding rubber to PMMA enhanced mechanical properties were obtained, while the impact strength was improved as the ceramic fillers acted as impact modifiers, absorbing the energy that resulted consecutive load application and transforming the material behavior from brittle to ductile [11]. Ceramic fillers have also been proved to improve hardness and fracture toughness of dental resins [12]. It also seems there is a synergistic effect between the tendency of fillers to fibrillate and the mechanical behavior of the matrix resin in governing the resulting ductility of the composite [13].

Other authors claim that addition of stiffening reinforcement to dental resins leads to lower ductility values, thus a more brittle material, because the rigid filler hinder the freedom of the polymer to reconfigure its structure after being stressed [13]. As studies showed controversial results regarding ductility, consecutive filler addition to PMMA, their influence on this characteristic of denture base materials is important to be further studied.

Among the researchers that attempted to find correlations between mechanical properties and clinical wear, Peutzfeldt suggested that resilience modulus can be used as a predictor for clinical wear, while resilience was shown to reflect in vivo wear performance [14], so Auer's supposition that resilience could influence polymer resistance to abrasion has been demonstrated [15]. Albers considered that cracks could be responsible of abrasion initiation [16] and his opinion was lately sustained by Peutzfeldt [14]. 
In dentistry acrylic resins are used inside the oral cavity, so their behavior and properties in the oral environment are of great importance. Although an ideal material should have high chemical and thermal stability, dental resins can absorb substances from the oral medium and release components in the surrounding environment $[17,18]$. Solubility of denture base materials results from the leaching out of residual monomer and also water soluble additives into the oral fluids, being a possible cause for tissue irritation, while water sorption affects the mechanical properties (acting as a plasticizer) and as well the dimensional stability and colour [17]. Acrylic resins homogeneity can influence water sorption and solubility [19], the more homogenous resins absorbing less water than the porous ones [20], as porosities permit fluid circulation through the network [21].

In our study we added both silver nanoparticles and graphene to a PMMA denture base resin, in order to improve its mechanical, physical and antibacterial properties.

\section{RESULTS AND DISCUSSION}

We computed mean, standard deviation, minimum and maximum values for each set of 10 values for each sample for solubility, ductility and resilience. One way ANOVA was used to analyze the variation in means for the different types of samples. Paired t-test was used to do pairwise comparisons of samples. A " $p$ " value less than 0.05 will indicate statistically significant differences.

For the reinforced material the fracture occurred at slightly lower stress and strain values, indicating that graphene silver nanoparticles addition reduces slightly the ductility of the reinforced resin, compared to the control, but the differences are not statistically significant. The mean values are presented in figure 1. The lowest mean value was found in the sample P1 (0.64) while the highest mean value was found in the control sample $M(0.68)$, while the P2 sample showed intermediate mean values. The measured values ranged between 0.42 and $0.96 \mathrm{~mm}$.

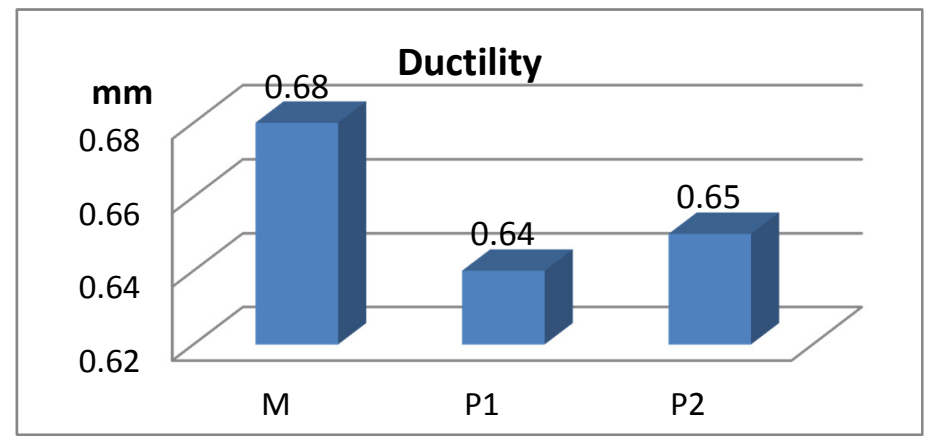

Figure 1. Mean Values of Ductility $(\mathrm{mm})$ for PMMA with graphene samples $(\mathrm{P} 1, \mathrm{P} 2)$ and control 
CECILIA BACALI, SMARANDA BUDURU, VIVI NASTASE, ANTARINIA CRACIUN, DOINA PRODAN, MARIANA CONSTANTINIUC, MANDRA BADEA, MARIOARA MOLDOVAN, CODRUTA SAROSI

Fillers distribution inside the PMMA matrix can be observed in the SEM images, figure 2. No visible pores and bubbles were observed in the polymer when viewed without magnification. The aspect of the fractured surface shows minimal differences between the examined samples. SEM images reveal a smooth surface with rapid cracks (evidenced by the arrows), indicating a brittle fracture.
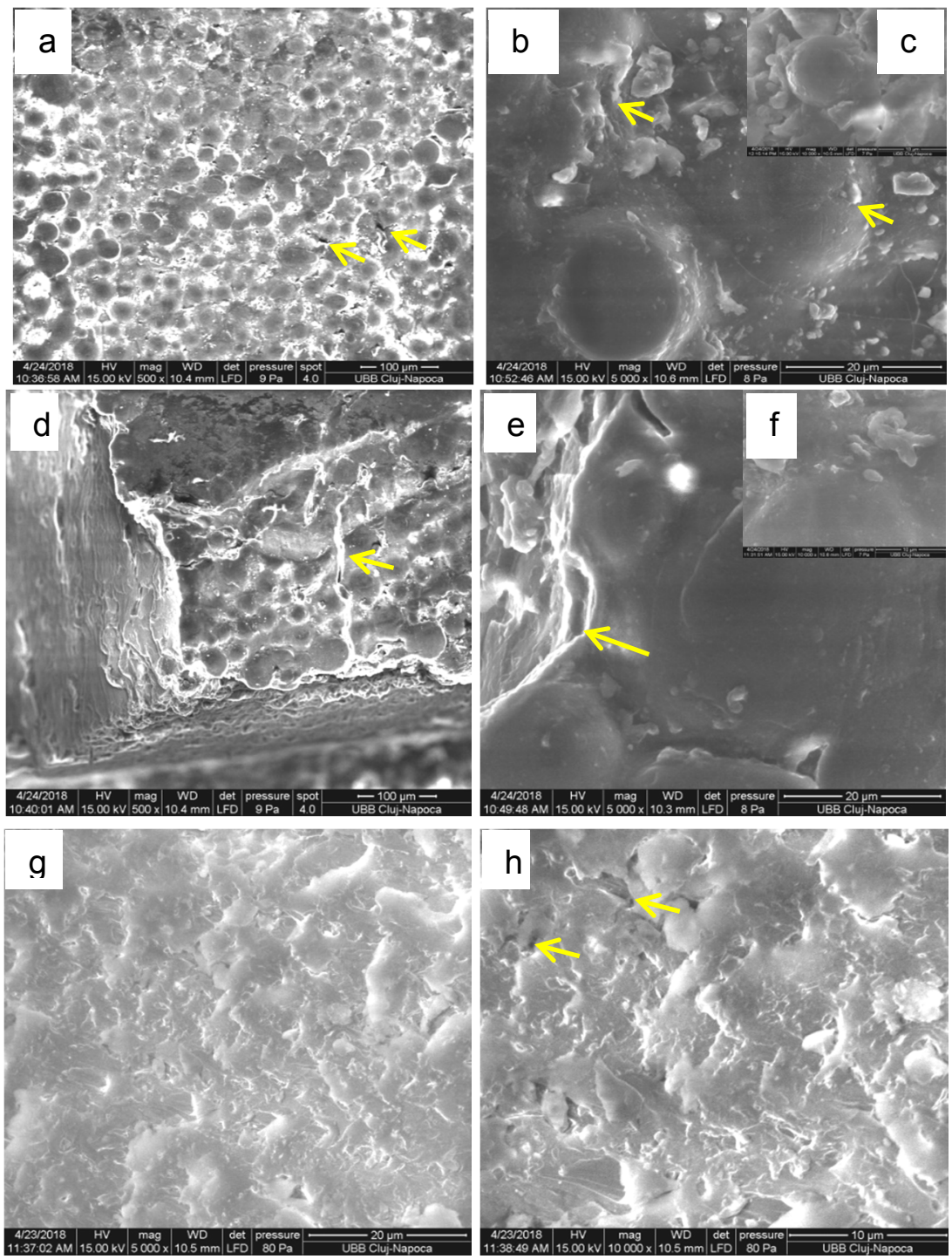

Figure 2. SEM images of the PMMA with graphene (G-Ag) - P1 (a, b, c) and $P 2(d, e, f, g, h)$ samples on the fractured surfaces at different magnification 500x, 5000x and 10000x 
The SEM images revealed that the particles with graphene were well distributed and dispersed in the PMMA matrix when $1 \%$ and $2 \%$ were used in the composition of P1 and P2. Some of the graphene nanoparticles were pulled out from the fractured surfaces of the PMMA - based composite materials during the impact test. There were also some micro-cracks on their fractured surfaces.

Figure 3 shows the mean values for modulus of resilience measured for each group of ten samples (M, P1, P2). The registered values ranged between 1.7 and $6.24 \mathrm{~J} / \mathrm{m}^{3}$. On average, the highest modulus of resilience is achieved for the sample with $1 \% \mathrm{G}-\mathrm{Ag}$. The variance of mean values within the group is statistically significant $(p=0.00045)$. In pairwise comparisons, the difference between P1 (PMMA + 1\% G-Ag) and P2 (PMMA + 2\% G-Ag) has the lowest $p$ value $(0.0013)$, whereas for the other pairs it hovers about 0.05 (0.054 and 0.057 respectively).

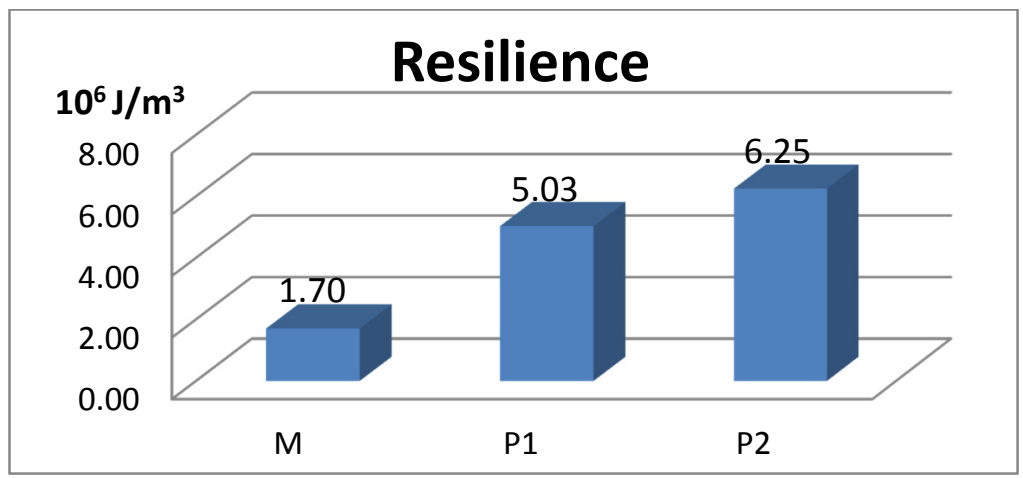

Figure 3. Mean values of modulus of resilience $\left(10^{6} \mathrm{~J} / \mathrm{m}^{3}\right)$ for the control and reinforced samples $\mathrm{P} 1$ and $\mathrm{P} 2$
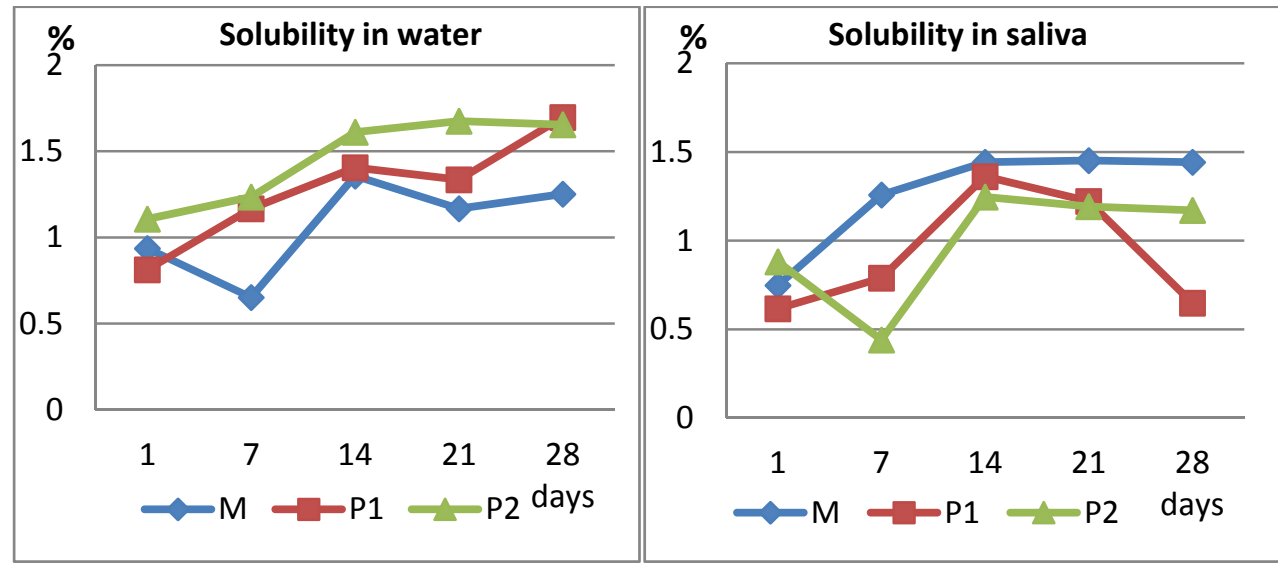

Figure 4. Mean values of solubility in water and saliva (\%) for the control (M) and reinforced samples P1 and P2 after 1, 7, 14, 21, 28 days of immersion 
The results show that for all three tested materials there are differences in 28 days between the mean values for the two test media, both in terms of absorption and solubility.

Samples reinforced with $1 \%$ wt. graphene silver nanoparticles showed higher mean values for the solubility in water and lower values for the solubility in saliva.

Samples reinforced with $2 \%$ wt. additives showed increased solubility both in water and saliva compared to control sample.

The lowest value was obtained for the sample P1 in saliva, while the highest value was obtain for the same sample in water.

The mean values for the solubility in water ranged between 0.0078 and $0.0112 \%$, the maximum mean value was found in the sample P1, and the minimum in the control sample. The mean values for the solubility in saliva ranged between 0.0059 and $0.0089 \%$, with a maximum value for the sample P2 and a minimum value for P1.

The P1 sample had the maximum mean value of water solubility, while the minimum values were found in the P2 sample after immersion in saliva.

Many researchers tried to improve denture base acrylic resins' mechanical properties by adding fillers of different type, sizes, shapes, in different proportions, in order to obtain stronger [22-27] and also less brittle materials [28]. Low ductility of dental resins is a key limitation, while increment of both the strength and ductility of matrix composites is still a challenge. Clustering is one of the major problems in nanoparticles reinforced composites [29]. On the other hand, high filler concentrations could decrease mechanical properties, as the lower concentrations permit a better distribution in the PMMA [30, 31]. Fillers addition beyond $1 \%$ wt leads to a deterioration of mechanical strength that can be attributed to filler agglomeration [7].

Ductility is a delicate problem in brittle materials, as it is difficult to predict: in low ductility materials it depends on the ultimate tensile strength and fracture energy, while in materials with added ductile second phase it varies with composition. Ductility is decreased by porosities and also by a week interface between phases that lead to low strength and premature failure. High toughness is found when fracture passes through both phases [32].

Addition of elastic and rigid fillers, such as nitrile rubber and ceramic fillers, for example, showed improved values of impact strength and fracture toughness, causing an increment in PMMA ductility [11]. Therefore, addition of materials with high ductility could improve the final ductility of the acrylic resins.

In this study we investigated the effect of adding silver nanoparticles and graphene to a commercial denture base acrylic resin. Silver nanoparticles, rigid structural fillers, were added to the material in order to obtain enhanced mechanical and also antibacterial properties. As the homogenous dispersion 
of silver nanoparticles into the PMMA matrix is difficult to be obtained because of the easy agglomeration of the nanoparticles and the high viscosity of the polymer [33], we associated them with graphene, in order to stabilize them.

Graphene is a lightweight and elastic material but also the strongest and stiffest material ever known so far and has remarkable mechanical properties. Although graphene has higher elastic modulus and tensile strength than graphene oxide, graphene oxide hydrophilicity/hydrophilic outer surface are beneficial for the aqueous procession of polymer nanocomposites [34]. While mechanically activated graphene is brittle, the cyclic epoxidic groups on graphene oxide make it ductile by dissipating strain energy and avoiding crack propagation through a covalent epoxide-to-ether functional group transformation [35]. Graphene oxide and its derivates have been lately used for polymer matrices mechanical properties enhancement. Severe internal porosity of the material can favour internal stresses, reducing denture durability [36], while the surface porosity enhances bacterial adhesion [37] and calculus deposition, affecting esthetics [38].

Increased modulus of resilience obtained for both reinforced resins could improve the abrasion resistance and consecutive resins' durability, as the cracks, that initiate abrasion need little energy to break the material and are likely to appear in materials with low modulus of resilience $[14,16]$. The mean values obtained for the resins with nanoparticle addition (5.02 and 6.24), are higher than those found by Peutzfeld in a study on acrylic resins, 0.67-2.40 $\mathrm{MJ} / \mathrm{m}^{3}$ [14].

Water sorption and solubility still remain a concern regarding dental materials, as they are critical problems that can influence a resin's durability [39]. They cause dimensional changes in the material that can determine internal stresses, favoring cracks and fractures. In our study the tests consisted in sample immersion in distilled water and artificial saliva at $37^{\circ} \mathrm{C}$ for 28 days, and mass weighting at certain intervals. Higher solubility values were found for the reinforced resins, excepting P1 sample in saliva, which showed a decrease. The higher solubility of the reinforced resins can be explained by the effect of fillers addition to PMMA, that decreases the degree of conversion and consecutive increases the amount of unreacted monomer [4], as the solubility is directly related to residual monomer releasing. Solvent's diffusion in the matrix can also lead to polymer dissolution and dispersion of the particles into the solvent. However, the values we found ranged between the accepted limits. The mean values we obtained were lower than the mean values $(0.03-0.13 \%)$ found in another study on water solubility of denture base acrylic resins [40].

Addition of $1 \%$ graphene silver nanoparticles showed favorable effects on resilience modulus and solubility in saliva, while a concentration of $2 \%$ wt increased solubility in water and saliva but also improved the modulus of resilience. Filler incorporation into PMMA was accompanied by a reduction in ductility, although without a statistical significance. 
CECILIA BACALI, SMARANDA BUDURU, VIVI NASTASE, ANTARINIA CRACIUN, DOINA PRODAN, MARIANA CONSTANTINIUC, MANDRA BADEA, MARIOARA MOLDOVAN, CODRUTA SAROSI

\section{CONCLUSIONS}

Different concentrations of graphene-silver nanoparticles, added to PMMA in order to induce antibacterial properties and improve fracture strength, can have different effects on resin's characteristics. We found that a concentration of $1 \%$ wt graphene silver nanoparticles has a beneficial effect on the resins' modulus of resilience and solubility in saliva, but it decreases ductility. A concentration of $2 \%$ improves resilience and could have good perspectives regarding durability, but increases solubility both in water and saliva and reduces resin's ductility.

\section{EXPERIMENTAL SECTION}

\section{Materials}

Castavaria (Vertex Dental, 3769 Soesterberg, The Netherlands), commercial denture base material was used in our tests.

The graphene-silver nanoparticles (G-Ag) composite was synthesized through the Radio-Frequency Catalytic Chemical Vapor Deposition (RF-CCVD) method [41] [Jatania] using silver nanoparticles distributed over magnesium oxide (Agx/MgO, where $\mathrm{x}=3 \mathrm{wt} \%$ ) and graphene oxide, obtained as previously described [42]. Mixing of G-Ag with acrylic denture material was done in $95 \%$ ethyl alcoholic solution, at room temperature, under continuous stirring, for 30 minutes. The compounds were then dried in the oven at $40^{\circ} \mathrm{C}$. Synthesis was performed using a methane flow rate of $80 \mathrm{~mL} / \mathrm{min}$ and a reaction time of 60 minutes [43].

\section{Sample Preparation}

The experimental materials were obtained from a commercial denture base auto-polymerizing acrylic resin, Castavaria (Vertex Dental, 3769 AV Soesterberg, Netherlands). The control sample contains only the commercial material (M), while samples contain also 1\% (P1) and 2\% (P2) graphene-Ag nanoparticles respectively.

The samples were obtained by mixing Castavaria resin powder with graphene silver nanoparticles ( $1 \%$ and $2 \%$ ), using a lab vibrator. Acrylic resin, with and without added fillers, was mixed in the recommended ratio $(1 \mathrm{ml} / 0.95 \mathrm{~g}$ monomer: $1.7 \mathrm{~g}$ polymer) and then poured into a silicone mold. The experimental composites were cured for 30 minutes, at $55^{\circ} \mathrm{C}$ and $2.5 \mathrm{Barr}$, as described in 
the commercial product specifications and sticks of $150 \mathrm{~mm}$ in length and 15 $\mathrm{mm}$ diameter were obtained. The sticks were then sectioned using a cutting device (Isomet 1000 Precision Saw, Buehler) in $15 \times 1 \mathrm{~mm}$ disks, further used as samples for the solubility tests. For flexural strength assessment, 10 rectangular samples $(25 \times 2 \times 2 \mathrm{~mm})$ for each material were fabricated using silicone molds in the same processing conditions.

\section{Methods}

In our study we assessed the water solubility through the loose of mass [19], according to ISO recommended methods [44]. The tests were performed at room temperature; after initial weighting $\left(\mathrm{m}_{1}\right)$ using a digital analytical balance (Adventurer AX224M, Ohaus), specimens were immersed in distilled water at $37^{\circ} \mathrm{C}$ and weighted again - till a constant weight was obtained - at 2, 7, 14 and 28 days after careful drying with an absorbent paper and a 2 hours storing period in a desiccator $\left(\mathrm{m}_{3}\right)$.

Solubility, the property of a substance to dissolve in a solvent, is expressed as the reduction in a sample mass following the immersion in a solvent. We assessed solubility by determining the difference between the initial mass of the sample and its mass measured after immersion and then drying in a dessicator.

The water solubility were calculated as: Wsl $=100 \times\left(\left(m_{1}-m_{3}\right) / m_{1}\right)$.

Ductility represents the amount of energy per unit volume that a material can absorb prior to fracture. Ductility was assessed by determining the fracture stress and strain values. For an unnotched tensile bar, energy to break is related to the area under a stress-strain curve [8]. Modulus of resilience was calculated after determining the flexural strength and the modulus of elasticity using the formula $R=F^{2} / 2 E$, where $R$ is the modulus of resilience, $F$ is the flexural strength and $E$ is the modulus of elasticity.

The flexural strength was assessed with a Lloyd universal testing machine (Lloyd Instruments, Ametek, Farham, UK) using a 3-point bending test. The fracture surface of the specimens was examined using Inspect $S$, FEI Company Scanning Electron Microscope.

\section{ACKNOWLEDGEMENTS}

This study was supported through the PCD 7690/76/15.04.2016 grant, funded by the University of Medicine and Pharmacy luliu Hatieganu, Cluj-Napoca. 
CECILIA BACALI, SMARANDA BUDURU, VIVI NASTASE, ANTARINIA CRACIUN, DOINA PRODAN, MARIANA CONSTANTINIUC, MANDRA BADEA, MARIOARA MOLDOVAN, CODRUTA SAROSI

\section{REFERENCES}

1. P. SrinivasRao, P. Mahesh, H. C. Kumar, M. Reddi, N. Rao, Annals and Essences of Dentistry, 2012, 4, 25.

2. Z. Han, B. Zhu, R. Chen, Z. Huang, C. Zhu, X. Zhang, Materials \& Design, 2015, $65,1245$.

3. M. M. Gad, S. W. Fouda, F. A. Al-Harbi, R. Napankangas, A. Raustia, International Jourmal of Nanomedicine, 2017, 12, 3801.

4. F. Kundie, C. Azhari, A. Muchtar, Z. Ahmad, Journal of Physical Science, 2018, 29, 141.

5. D. Devaprakasam, P. V. Hatton, G. Möbus, B. J. Inkson, Journal of Physics: Conference Series, 2008, 126, 012057

6. P. Makvandi, N. Nikfarjam, N. S. Sanjani, N. T. Qazvini, Bulletin of Materials Science, 2015, 38, 1625.

7. S. Tripathy, P. Saini, D. Gupta, V. Choudhary, Journal of Materials Science, 2013, 48, 6223

8. Y. Zhang, D. Rodrigue, A. Ait-Kadi, Polymers and Polymer Composites, 2014, $12,17$.

9. G. Zappini, A. Kammann, W. Wachter, Journal of Prosthetic Dentistry, 2003, 90, 578.

10. A. Muraikami, J. C. Behiri, W. Bonfield, Journal of Materials Science, 1988, 23, 2029.

11. A. O. Alhareb, H. M. Akil, Z. A. Ahmad, The Saudi Journal for Dental Research, 2017, 8, 26.

12. S. O. Alsharif, H. B. M. Akil, N. A. Abbas, N. A. A. El-Aziz, Z. A. B. Ahmad, Materials and Design, 2014, 54, 430.

13. B. Patham, P. Poornendu, M. Thejaswini, Journal of Polymers, 2013, 424015.

14. A. Peutzfeldt, E. Asmussen, Dental Materials, 1992, 8, 146.

15. E. E. Auer, "Abrasion resistance. In: Encyclopedia of polymer science and technology", John Wiley\&Sons Inc., 1965. New York. 1, 7.

16. H. F. Albers, "Tooth colored restorations: A text for selection, placement and finishing. $7^{\text {th }}$ Edition", Alto Books 1985 California., USA.

17. B. Agarwal, C. B.S. Patel, B. P. Singh, A. Kumar, M. Singh, N. Singh, Indian Journal of Applied Research, 2015, 5, 41.

18. A. Picos, A. L. Rachisan, A. Dadarlat, Materiale Plastice, 2018, 55, 252.

19. V. M. Miettinen, P. K. Vallitu, D. T. Docent, Journal of Prosthetic Dentistry, 1997, $77,531$.

20. L. V. Lassila, P. K. Vallitu, Journal of Oral Rehabilitation, 2001, 28, 607.

21. J. Malacarne, R. M. Carvalho, M. F. de Goes, N. Svizero, D. H. Pashley, F. R. Tay, C. K. Yiu, M. R. Carrilho, Dental Materials, 2006, 22, 973.

22. S. Sava, M. Moldovan, C. Sarosi, A. Mesaros, D. Dudea, C. Alb, Materiale Plastice, 2015, 52, 90.

23. I. Cojocariu, M. Moldovan, M. Trif, D. Prodan, V. Popescu, I. Constantinescu, Materiale Plastice, 2009, 46, 383. 
24. M. Moldovan, C. Prejmerean, A. Colceriu, C. Tamas, G. Furtos, D. Prodan, M. Trif, C. Alb, S. Neamt, V. Popescu, Journal of Optoelectronics and Advanced Materials, 2007, 11, 3415.

25. S. Sava, C. Sarosi, S. Boboia, A. Tonea, C. Alb, D. Dudea. Studia UBB Chemia, 2015, 2,71 .

26. G. Furtos, M. Tomoaia-Costisel, C. Garbo, M. Senila, N. Jumate, I. Vida-Simiti, C. Prejmerean, Particulate Science and Technology, 2013, 31, 392.

27. C. Sarosi, Al. R. Biris, A. Antoniac, S. Boboia, C. Alb, I. Antoniac, M. Moldovan, Journal of Adhesion Science and Technology, 2016, 30,1779.

28. P. A. Hari, H. S. Mohammed, Annals of Essences of Dentistry, 2011, 3, 7.

29. J. Liu, Z. Chen, F. Zhang, G. Ji, M. Wang, Y. Ma, S. Zhong, Y. Wu, H. Wang, Materials Research Letters, 2018, 6, 406.

30. N. V. Asar, H. Albayrak, T. Korkmaz, I. Turilmaz, The Journal of Advanced Prosthodontics, 2013, 5, 241.

31. A. Sodagar, A. Bahador, S. Khalil, A. S. Shahroudi, M. Z. Kassaee, Journal of Prosthodontic Research, 2013, 57, 15.

32. R. M. German, "Particulate composites: Fundamentals and applications", Springer International Publishing, Switzerland, 2016, chapter 4.

33. E. H. Alsharaeh, Materials, 2016, 9, 458.

34. S. Kashyap, K. P. Pratihar, S. K. Behera, Journal of Alloys and Compounds, 2016, 684, 254.

35. X. Wei, L. Mao, R. A. Soler-Crespo, J. T. Paci, J. Huang, S. Nguyen, D. Horacio, Nature communications, 2017, 8, 14488.

36. J. F. Woofardt, P. Cleaton-Jones, P. Fatti, Journal of Prosthetic Dentistry, 1986, $55,393$.

37. M. Kattadiyil, R. Jekki, C. Goodacre, N. Baba, Journal of Prosthetic Dentistry, 2015, 114, 818.

38. S. Singh, J. N. Palaskar, S. Mittal, Contemporary Clinical Dentistry, 2013, 4, 147.

39. J. L. Garcia-Fierro, J. V. Aleman, Macromolecules, 1982, 15, 4.

40. M. R. S. Figuerôa, B. Conterno, C. A. G. Arrais, C. Y. C. Sugio, V. M. Urban, K. H. Neppelenbroek, Journal of Applied Oral Science, 2018, 26, e20170383.

41. A. Jatania, B. M. Shivalinga, European Journal of Dentistry, 2014, 8, 112.

42. D. Olteanu, A. Filip, C. Socaci, A. R. Biris, X. Filip, M. Coros, M. C. Rosu, F. Pogacean, C. Alb, I. Baldea, P. Bolfa, S. Pruneanu, Colloids and Surface B: Biointerfaces, 2015, 136, 791.

43. B. Zhang, P. Wei, Z. Zhou, T. Wei, Advanced Drug Delivery Review, 2016, 105, 145.

44. ISO 1567:1999 Dentistry-Denture base Polymers 